\title{
Correlation Between the Cardio-Ankle Vascular Index and Renal Resistive Index in Patients With Essential Hypertension
}

\author{
Takashi Hitsumoto
}

\begin{abstract}
Background: Renal resistive index (RRI) is a parameter determined by Doppler sonography that reflects renal hemodynamics. Significant relationships connecting increases in the RRI with cardiovascular risk factors and the incidence of cardiovascular disease in hypertensive patients have been reported. This cross-sectional study aimed to clarify the relationship between cardio-ankle vascular index (CAVI), a novel marker of arterial stiffness, and the RRI in patients with essential hypertension with the goal of primary prevention of cardiovascular disease.
\end{abstract}

Methods: The study included 245 patients undergoing treatment for essential hypertension ( 95 men and 150 women; mean age \pm standard deviation, $65 \pm 13$ years) with no history of cardiovascular disease. The CAVI and RRI were measured using commercial devices, and their relationships to various clinical parameters were examined.

Results: A significant positive correlation was observed between the CAVI and RRI $(r=0.43, P<0.001)$. Multiple regression analyses revealed a value of $\beta$ of $0.28(\mathrm{P}<0.001)$ when CAVI was evaluated as the independent and RRI as the dependent variable. Receiver-operating characteristic curve analysis indicated that the CAVI cutoff point for high RRI $(>0.70)$ was 9.0 with area under the curve of $0.700(\mathrm{P}<0.001)$.

Conclusion: The results from this study indicate that the CAVI varies directly with measures of renal vascular hemodynamics (RRI) in patients with essential hypertension. These findings identified a cardiovascular risk value of the CAVI from the perspective of renal hemodynamics as 9.0 in this patient population.

Keywords: Cardio-ankle vascular index; Renal resistive index; Oxidative stress; Renin-angiotensin system inhibitor; Hypertension

\section{Introduction}

Renal function is directly associated with the pathogenesis of

Manuscript submitted January 25, 2020, accepted February 17, 2020

Hitsumoto Medical Clinic, 2-7-7, Takezakicyou, Shimonoseki City, Yamaguchi 750-0025, Japan. Email: thitsu@jcom.home.ne.jp

doi: https://doi.org/10.14740/cr1026 hypertension. In clinical practice, renal function can be evaluated using biomarkers such as estimated glomerular filtration rate (eGFR) and urinary protein or albumin concentration. These biomarkers have also been established as important predictors for cardiovascular events [1,2]. Recent clinical studies have indicated that the renal resistive index (RRI) is also a useful and novel marker for evaluating renal function [3]; the RRI reflects renal hemodynamics and is determined using Doppler sonography. Several groups have reported associations linking RRI to cardiovascular risk factors or incidence of cardiovascular disease in hypertensive patients [4-6].

The cardio-ankle vascular index (CAVI) is a novel physiological marker of arteriosclerosis that reflects the stiffness of the aorta and the femoral and tibial arteries and is not affected by blood pressure measurements [7]. A number of clinical studies have revealed the importance of the CAVI as a marker for cardiovascular risk factors [8-11], and other groups have documented significant relationships between the CAVI and markers of renal function such as eGFR and urinary albumin concentration $[12,13]$. Taken together, these results suggest that the CAVI provides a reflection of renal hemodynamics. However, at present, limited information is available regarding the relationships between CAVI and RRI in hypertensive patients. This study examined the relationship between the CAVI and RRI in patients with essential hypertension with the goal of primary prevention of cardiovascular disease.

\section{Materials and Methods}

\section{Patients}

This cross-sectional study was conducted at the Hitsumoto Medical Clinic in the city of Shimonoseki in Japan from June 2017 to May 2019. The study population comprised 245 outpatients receiving treatment for essential hypertension who successfully underwent procedures for determination of the CAVI and an ultrasonographic examination to obtain the RRI. Exclusion criteria included a history of cardiovascular disease, including stroke, coronary artery disease and/or peripheral arterial disease. Patients with a history of renal artery stenosis, acute renal insufficiency and/or end-stage renal disease were also excluded from this study. The patient population included 
95 men and 150 women with a mean age \pm standard deviation (SD) of $65 \pm 13$ years. The study was approved by the Institutional Review Board of the Hitsumoto Medical Clinic (approval number 2017-05) and was conducted in compliance with the Declaration of Helsinki.

\section{Measurement of CAVI}

The CAVI was measured for each patient using a Vascular Screening System (VaSera) instrument (Fukuda Denshi Co., Ltd, Tokyo, Japan) as described in previous reports [7]. Briefly, the brachial and ankle pulse waves were determined using inflatable cuffs with the pressure maintained between 30 and $50 \mathrm{~mm} \mathrm{Hg}$ to ensure minimal impact on systemic hemodynamics. Systemic blood and pulse pressures were determined simultaneously with the participant in the supine position and after a 10-min rest period. CAVI was calculated using the following formula: $\mathrm{CAVI}=\mathrm{a}\left\{(2 \rho / \Delta \mathrm{P}) \times \ln (\mathrm{Ps} / \mathrm{Pd}) \times \mathrm{PWV}^{2}\right\}+\mathrm{b}$, where $\mathrm{a}$ and $\mathrm{b}$ are constants, $\rho$ is blood density, $\Delta \mathrm{P}$ is $\mathrm{Ps}-\mathrm{Pd}$, Ps is systolic blood pressure, $\mathrm{Pd}$ is diastolic blood pressure and PWV is pulse wave velocity. The average coefficient of variation was $<5 \%$; this value is small enough for clinical application and indicates good reproducibility [7].

\section{Determination of RRI by ultrasonography}

The RRI was determined by ultrasonography performed using a high-resolution ultrasonographic scanner with a $3.0-\mathrm{MHz}$ convex array probe (HI VISION Avius, Hitachi Medical Corporation, Tokyo, Japan) as previously reported [14]. Briefly, RRI was measured in three segmental arteries (superior, middle and inferior) of each kidney; all results were averaged to generate a mean value for each patient. RRI was calculated from the peak systolic and end-diastolic velocities using the following equation: (peak systolic velocity - end-diastolic velocity)/peak systolic velocity. All measurements were performed by an experienced physician who did not have access to other patient-related data.

\section{Evaluation of cardiovascular risk factors}

Obesity was estimated for each participant using body mass index (weight (in $\mathrm{kg}$ )/height (in $\mathrm{m}^{2}$ )). A participant was defined as a smoker if he/she smoked at least one cigarette per day during the previous 28 days. Right brachial blood pressure was measured twice with a mercury sphygmomanometer with the participant in a sitting position; an average of two independent readings was used to determine systolic and diastolic blood pressures. Diabetes mellitus was defined as a fasting blood glucose $\geq 126 \mathrm{mg} / \mathrm{dL}$, hemoglobin A1c $\geq 6.5 \%$ and/or the ongoing use of antidiabetic medications or exogenous insulin. Dyslipidemia was defined as low-density lipoprotein cholesterol $\geq 140 \mathrm{mg} / \mathrm{dL}$, high-density lipoprotein cholesterol $\leq 40$ $\mathrm{mg} / \mathrm{dL}$, triglycerides $\geq 150 \mathrm{mg} / \mathrm{dL}$ and/or current use of lipidlowering medication. Blood samples were collected from the antecubital veins in the morning after $12 \mathrm{~h}$ of fasting. Blood glucose, serum lipid and creatinine levels, and oxidative stress markers were measured using standard laboratory procedures. The estimated glomerular filtration rate (eGFR) was calculated using the adjusted Modification of Diet in Renal Disease Study equation proposed by the working group of the Japanese Chronic Kidney Disease Initiative [15]. Oxidative stress markers were evaluated by testing reactive oxygen metabolites (dROMs; Diacron, Grosseto, Italy) [16].

\section{Statistical analyses}

Data were analyzed using the Stat View-J 5.0 (HULINKS, Tokyo, Japan) and MedCalc for Windows version 14.8.1 (MedCalc Software, Ostend, Belgium) and are presented as mean $\pm \mathrm{SD}$ values. Between-group comparisons were performed using the Student's $t$-test or the Mann-Whitney U-test. Correlation coefficients were estimated using the Pearson or Spearman rank-order correlation analysis. Multiple regression analyses were performed and receiver-operating characteristic (ROC) curves were constructed. The maximum Youden index [17] was used to determine the optimal CAVI cutoff levels at high RRI. A $\mathrm{P}$ value $<0.05$ was considered as statistically significant.

\section{Results}

\section{Patient characteristics}

Table 1 summarizes the patient characteristics. The mean RRI $\pm \mathrm{SD}$ was $0.69 \pm 0.07$ (range, $0.52-0.87$ ), and the mean CAVI $\pm \mathrm{SD}$ was $8.7 \pm 1.4$ (range, $6.2-13.8$ ), both with near normal distributions. Table 2 shows the comparisons of clinical parameters of the calcium channel blocker (CCB) use and renin-angiotensin system (RAS) inhibitor use patients. RRI and CAVI were significantly lower in patients with RAS inhibitor use than in those with CCB use.

\section{Correlations between the CAVI and the RRI with respect to clinical parameters}

The findings revealed a significant correlation between the CAVI and the RRI (Fig. 1). Table 3 presents the relationships linking the RRI and the CAVI to several clinical parameters. There were significant correlations between RRI and patient age, systolic blood pressure, diastolic pressure, eGFR, oxidative stress (as per the d-ROMs test) and therapeutic RAS inhibitor usage. There were also significant correlations between the CAVI and smoking habits, diabetes-related factors, eGFR, oxidative stress, and RAS inhibitor and statin use.

\section{Multiple regression analyses for RRI}

Table 4 summarizes the results of a multiple regression analysis with RRI as the dependent variable; independent variables 
Table 1. Characteristics of Patients

\begin{tabular}{ll}
\hline $\mathrm{n}$ (male/female) & $245(95 / 150)$ \\
Age (years) & $65 \pm 13$ \\
Body mass index $\left(\mathrm{kg} / \mathrm{m}^{2}\right)$ & $22.6 \pm 3.7$ \\
Current smoker, $\mathrm{n}(\%)$ & $63(26)$ \\
Systolic blood pressure (mm Hg) & $138 \pm 10$ \\
Diastolic blood pressure (mm Hg) & $87 \pm 10$ \\
Pulse rate (/min) & $66 \pm 11$ \\
Diabetes mellitus, $\mathrm{n}(\%)$ & $99(40)$ \\
Fasting blood glucose (mg/dL) & $114 \pm 25$ \\
Hemoglobin A1c (\%) & $6.5 \pm 1.3$ \\
Dyslipidemia, $\mathrm{n}(\%)$ & $155(63)$ \\
Total cholesterol (mg/dL) & $210 \pm 39$ \\
LDL-cholesterol (mg/dL) & $133 \pm 36$ \\
Triglyceride (mg/dL) & $130 \pm 67$ \\
HDL-cholesterol (mg/dL) & $50 \pm 13$ \\
eGFR (mL/min/1.73 m²) & $65 \pm 21$ \\
d-ROMs test (U. CARR) & $296 \pm 96$ \\
RRI & $0.69 \pm 0.07$ \\
CAVI & $8.7 \pm 1.4$ \\
Medication & $185(76)$ \\
$\quad$ CCB, $\mathrm{n}(\%)$ & $136(56)$ \\
$\quad$ RAS inhibitor, $\mathrm{n}(\%)$ & $51(21)$ \\
\hline$\quad$ Statin, $\mathrm{n}(\%)$ & $102(42)$ \\
\hline
\end{tabular}

Continuous values are mean \pm SD. LDL: low-density lipoprotein; HDL: high-density lipoprotein; eGFR: estimated glomerular filtration rate; d-ROMs: derivatives of reactive oxygen metabolites; RRI: renal resistive index; CAVI: cardio-ankle vascular index; CCB: calcium channel blocker; RAS: renin-angiotensin system.

include the seven significant variables for RRI that were identified in univariate analysis. CAVI, d-ROMs oxidative stress, RAS inhibitor use and eGFR were also examined as independent variables.

\section{ROC curve analysis}

Figure 2 includes an analysis of the ROC curve generated for the detection of high RRI as $>0.70$ based on previous reports $[18,19]$. The maximum Youden's index indicated that a CAVI of $>9.0$ was the optimal cutoff point for the determination of high RRI (area under the curve $=0.700, \mathrm{P}<0.001$ ), with a true positive rate of $59.4 \%$ and a false positive rate of $20.1 \%$.

\section{Discussion}

This study aimed to clarify the relationships between the CAVI, a novel marker of arterial stiffness, and the RRI in patients with essential hypertension. Previous studies have revealed significant associations between the physiological marker of arterial stiffness and RRI [20,21]. Even though correlation coefficient between the CAVI and the RRI in univariate analysis was relatively low level $(\mathrm{r}=0.43)$, the results of this study confirmed these reports and further demonstrated that the CAVI has a direct, independent association with the RRI in this patient population. Furthermore, the analysis of the ROC curve indicated a risk value of 9.0 for the CAVI for primary cardiovascular incidence from perspective of renal hemodynamics. Similar results were obtained with oxidative stress (d-ROMs test) and RAS inhibitor use as independent variables and RRI as the dependent variable.

In theory, the RRI measures vascular resistance at sites that are distal from the point of examination. As such, the RRI measured in the segmental arteries may reflect distal microvascular function in kidney. By contrast, the CAVI reflects stiffness of the larger elastic and muscular arteries. The independent association between the CAVI and RRI revealed in this study likely reflects the close relationship between macrovascular and microvascular functions in patients with essential hypertension. Several previous reports have described these relationships [22-24]. For example, Safar et al reported that increased stiffness of the large arteries led to elevated pulse pressures, a factor that may ultimately lead to kidney damage [22]. Another study reported that elevated RRI may contribute to long-term, systemic arterial stiffening possibly in association with renal dysfunction [24]. As such, the results of this study suggest an important association between macrovascular and microvascular dysfunction that may be an underlying factor in the progression of systemic atherosclerosis.

Several groups have explored the relationships between oxidative stress and vascular dysfunction in the kidney [25, 26]. The results of this study document an independent association between d-ROMs and RRI; these results suggest that oxidative stress has a crucial role in promoting resistance of the renal vasculature in patients with essential hypertension. Likewise, several clinical studies noted significant relationships between the physiological markers of arterial stiffness, including the CAVI and oxidative stress [27-29]. The results presented here also reveal significant correlations between the CAVI and oxidative stress; these findings indicate that therapeutics designed to limit oxidative stress can be effective in maintaining healthy arterial function.

Recent basic and clinical studies have indicated the RAS plays a crucial role in promoting the pathogenesis of renal dysfunction and likewise, and that of RAS inhibitors in preventing the progression of renal damage [30-32]. Watanbe et al reported that the RAS inhibitor, valsartan, promoted significant reductions in the RRI in patients with essential hypertension [33]. The results presented here indicate that RRI was significantly lower in patients with RAS inhibitor use than in those with CCB use. Furthermore, RAS inhibitor use is directly associated with observed decreases in the RRI; RAS inhibitors may be considered as potential therapeutics for hypertensive patients with high RRI. Other reports concluded that administration of RAS inhibitor improved CAVI more than CCB $[34,35]$. This study also indicates that CAVI was significantly lower in patients with RAS inhibitor use than in those with 
Table 2. Comparisons of Clinical Parameters of the CCB Use and RAS Inhibitor Use Patients

\begin{tabular}{|c|c|c|c|}
\hline & CCB & RAS inhibitor & P value \\
\hline n (male/female) & $101(41 / 60)$ & $52(19 / 33)$ & 0.629 \\
\hline Age (years) & $66 \pm 14$ & $64 \pm 13$ & 0.342 \\
\hline Current smoker, n (\%) & $28(28)$ & $13(25)$ & 0.721 \\
\hline Systolic blood pressure (mm Hg) & $139 \pm 11$ & $139 \pm 10$ & 0.942 \\
\hline Diabetes mellitus, n (\%) & $41(41)$ & $24(46)$ & 0.513 \\
\hline Fasting blood glucose (mg/dL) & $115 \pm 25$ & $117 \pm 26$ & 0.717 \\
\hline Hemoglobin A1c (\%) & $6.7 \pm 1.4$ & $6.4 \pm 1.2$ & 0.096 \\
\hline Dyslipidemia, n (\%) & $66(65)$ & $32(62)$ & 0.645 \\
\hline HDL-cholesterol (mg/dL) & $49 \pm 13$ & $52 \pm 13$ & 0.227 \\
\hline eGFR (mL/min/1.73 m²) & $63 \pm 22$ & $68 \pm 25$ & 0.146 \\
\hline d-ROMs test (U. CARR) & $311 \pm 94$ & $283 \pm 97$ & 0.098 \\
\hline RRI & $0.71 \pm 0.07$ & $0.68 \pm 0.04$ & 0.006 \\
\hline CAVI & $9.2 \pm 1.5$ & $8.4 \pm 0.9$ & $<0.001$ \\
\hline
\end{tabular}

Data were evaluated in patients with single-agent. Continuous values are mean \pm SD. CCB: calcium channel blocker; RAS: renin-angiotensin system; LDL: low-density lipoprotein; HDL: high-density lipoprotein; eGFR: estimated glomerular filtration rate; d-ROMs: derivatives of reactive oxygen metabolites; RRI: renal resistive index; CAVI: cardio-ankle vascular index.

CCB use. Taken together, these studies suggest that RAS inhibitors may be of critical importance from the perspective of both macrovascular and microvascular functions.

It is useful to know the target cutoff level of the CAVI for predicting abnormal RRI levels among our patients diagnosed with essential hypertension. This study clarified the clinical

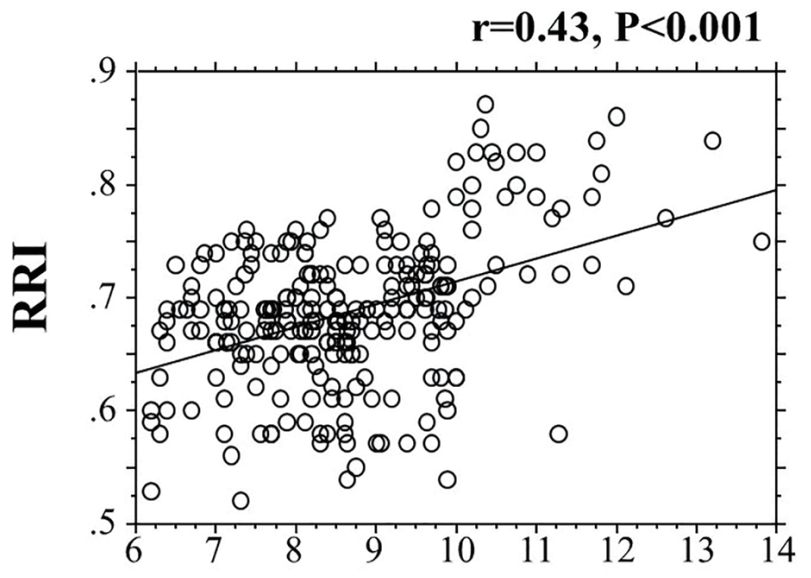

\section{CAVI}

Figure 1. The correlation between the CAVI and the RRI. CAVI: cardioankle vascular index; RRI: renal resistive index. usefulness of assessing the CAVI for detecting high RRI ( $>$ $0.70)$, demonstrated as a predictor of hypertension-related organ damage or mortality including cardiovascular death [18, 19]. Analysis of the ROC curve indicated that a CAVI of $>9.0$ was the optimal cutoff point for predicting high RRI. Several clinical studies have reported that a CAVI $\geq 9.0$ is a risk factor for cardiovascular events [36, 37]. This study also suggests that the hypertension-related organ damage and/or incidence of cardiovascular disease may be decreased in patients with essential hypertension by maintaining the CAVI at $\leq 9$.

\section{Limitations}

This study has several limitations. First, treatment of essential hypertension in this patient population varied and was not considered a part of the study design; any of these medications together with those used to avert other cardiovascular risk factors might have influenced the results. Second, as angiography, computed tomography and/or magnetic resonance imaging was not performed on all study patients; thus, cases of asymptomatic cardiovascular disease may have remained undetected. Finally, as this was a single-center cross-sectional study focused on a relatively small population, a prospective study capable of enrolling a substantially larger number of participants would be necessary to confirm the present findings and conclusions. 
Table 3. Relationship Between RRI, CAVI and Various Clinical Parameters

\begin{tabular}{|c|c|c|}
\hline & \multicolumn{2}{|c|}{$\mathbf{r}$} \\
\hline & RRI & CAVI \\
\hline Sex $($ female $=0$, male $=1)$ & 0.06 & 0.10 \\
\hline Age & $0.19 * *$ & $0.39 * * *$ \\
\hline Body mass index & -0.12 & -0.09 \\
\hline Current smoker $($ no $=0$, yes $=1)$ & 0.05 & $0.17 * *$ \\
\hline Systolic blood pressure & $0.13^{*}$ & 0.04 \\
\hline Diastolic blood pressure & $-0.19 * *$ & -0.10 \\
\hline Pulse rate & -0.03 & 0.05 \\
\hline Diabetes mellitus (no $=0$, yes $=1$ ) & -0.01 & $0.18 * *$ \\
\hline Fasting blood glucose & 0.06 & $0.19^{* *}$ \\
\hline Hemoglobin A1c & 0.03 & $0.22 * * *$ \\
\hline Dyslipidemia $($ no $=0$, yes $=1)$ & 0.04 & -0.04 \\
\hline Total cholesterol & 0.03 & 0.09 \\
\hline LDL-cholesterol & 0.03 & 0.09 \\
\hline Triglyceride & 0.02 & 0.07 \\
\hline HDL-cholesterol & 0.04 & -0.05 \\
\hline eGFR & $-0.29 * * *$ & $-0.34 * * *$ \\
\hline d-ROMs test & $0.30 * * *$ & $0.31 * * *$ \\
\hline $\mathrm{CCB}($ no $=0$, yes $=1)$ & 0.06 & 0.12 \\
\hline RAS inhibitor $($ no $=0$, yes $=1)$ & $-0.24 * * *$ & $-0.31 * * *$ \\
\hline$\beta$-blocker $($ no $=0$, yes $=1)$ & 0.12 & -0.06 \\
\hline Statin $($ no $=0$, yes $=1)$ & -0.03 & $-0.15^{*}$ \\
\hline
\end{tabular}

$r$ expressed correlation coefficient. ${ }^{*} P<0.05$, ${ }^{* *} P<0.01$, ${ }^{* * *} P<0.001$ RRI: renal resistive index; CAVI: cardio-ankle vascular index; LDL: lowdensity lipoprotein; HDL: high-density lipoprotein; eGFR: estimated glomerular filtration rate; d-ROMs: derivatives of reactive oxygen metabolites; CCB: calcium channel blocker; RAS: renin-angiotensin system.

\section{Conclusions}

In conclusion, this study revealed an independent association

Table 4. Multiple Regression Analyses for RRI

\begin{tabular}{lll}
\hline Variables & $\boldsymbol{\beta}$ & P value \\
\hline CAVI & 0.28 & $<0.001$ \\
d-ROMs test & 0.15 & 0.009 \\
RAS inhibitor & -0.14 & 0.019 \\
eGFR & -0.13 & 0.043 \\
Systolic blood pressure & -0.11 & 0.108 \\
Diastolic blood pressure & 0.10 & 0.235 \\
Age & 0.03 & 0.693 \\
\hline
\end{tabular}

$\mathrm{R}^{2}=0.30, \mathrm{P}<0.001 . \mathrm{RRI}$ : renal resistive index; CAVI: cardio-ankle vascular index; d-ROMs: derivatives of reactive oxygen metabolites; RAS: renin-angiotensin system; eGFR: estimated glomerular filtration rate; $\beta$ : standardized regression coefficient; $R^{2}$ : coefficient of determination.

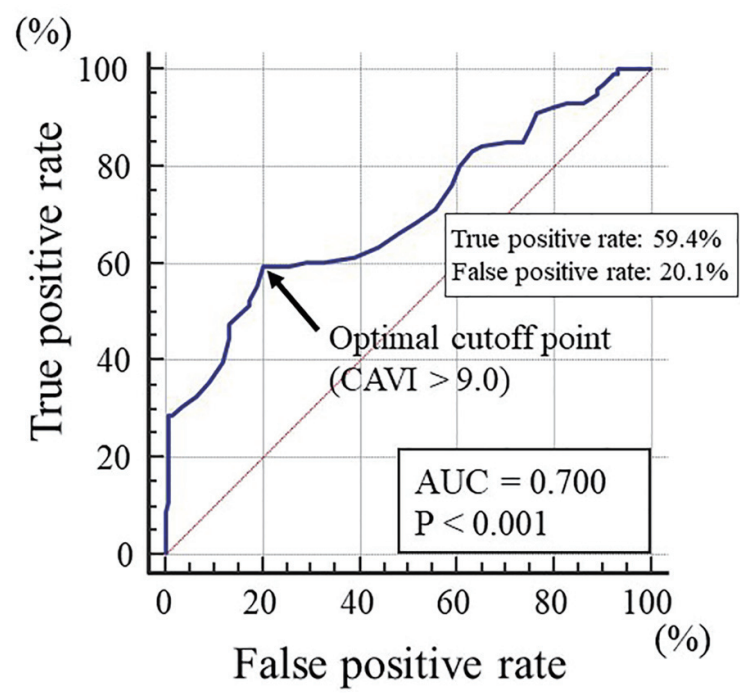

Figure 2. The receiver-operating characteristic curve analysis for the detection of high RRI based on the CAVI. The maximum Youden's index indicated that a CAVI of $>9.0$ was the optimal cutoff point for the determination of high RRI (area under the curve $=0.700, P<0.001$ ), with a true positive rate of $59.4 \%$ and a false positive rate of $20.1 \%$. RRI: renal resistive index; CAVI: cardio-ankle vascular index; AUC: area under the curve.

between the CAVI and the RRI. These results suggest that the CAVI may be a reflection of renal hemodynamics in patients with essential hypertension. Moreover, the cardiovascular risk value of the CAVI from the perspective of renal hemodynamics was determined to be 9.0 in this patient population.

\section{Acknowledgments}

The author would like to thank Michael Ryuta Yu for his assistance in the preparation of manuscript. Also, thanks to all the included patients in this study.

\section{Financial Disclosure}

None to declare.

\section{Conflict of Interest}

None to declare.

\section{Informed Consent}

All patients provided informed consent.

\section{Author Contributions}

The author was involved in preparing the study design as well 
as in the acquisition, analysis and interpretation of data.

\section{Data Availability}

The author declares that data supporting the findings of this study are available within the article.

\section{References}

1. Bouchi R, Babazono T, Yoshida N, Nyumura I, Toya K, Hayashi T, Hanai K, et al. Association of albuminuria and reduced estimated glomerular filtration rate with incident stroke and coronary artery disease in patients with type 2 diabetes. Hypertens Res. 2010;33(12):1298-1304.

2. Liu M, Li XC, Lu L, Cao Y, Sun RR, Chen S, Zhang PY. Cardiovascular disease and its relationship with chronic kidney disease. Eur Rev Med Pharmacol Sci. 2014;18(19):2918-2926.

3. Viazzi F, Leoncini G, Derchi LE, Pontremoli R. Ultrasound Doppler renal resistive index: a useful tool for the management of the hypertensive patient. J Hypertens. 2014;32(1):149-153.

4. Tedesco MA, Natale F, Mocerino R, Tassinario G, Calabro R. Renal resistive index and cardiovascular organ damage in a large population of hypertensive patients. J Hum Hypertens. 2007;21(4):291-296.

5. Doi Y, Iwashima Y, Yoshihara F, Kamide K, Takata H, Fujii T, Kubota Y, et al. Association of renal resistive index with target organ damage in essential hypertension. Am J Hypertens. 2012;25(12):1292-1298.

6. Doi Y, Iwashima Y, Yoshihara F, Kamide K, Hayashi S, Kubota Y, Nakamura S, et al. Renal resistive index and cardiovascular and renal outcomes in essential hypertension. Hypertension. 2012;60(3):770-777.

7. Shirai K, Utino J, Otsuka K, Takata M. A novel blood pressure-independent arterial wall stiffness parameter; cardio-ankle vascular index (CAVI). J Atheroscler Thromb. 2006;13(2):101-107.

8. Gohbara M, Iwahashi N, Sano Y, Akiyama E, Maejima N, Tsukahara K, Hibi K, et al. Clinical impact of the cardioankle vascular index for predicting cardiovascular events after acute coronary syndrome. Circ J. 2016;80(6):14201426.

9. Matsushita K, Ding N, Kim ED, Budoff M, Chirinos JA, Fernhall B, Hamburg NM, et al. Cardio-ankle vascular index and cardiovascular disease: Systematic review and meta-analysis of prospective and cross-sectional studies. J Clin Hypertens (Greenwich). 2019;21(1):16-24.

10. Hitsumoto T. Clinical usefulness of the cardio-ankle vascular index as a predictor of primary cardiovascular events in patients with chronic kidney disease. J Clin Med Res. 2018;10(12):883-890.

11. Hitsumoto T. Efficacy of the reactive oxygen metabolite test as a predictor of initial heart failure hospitalization in elderly patients with chronic heart failure. Cardiol Res. 2018;9(3):153-160.

12. Kubozono T, Miyata M, Ueyama K, Nagaki A, Hamasaki
S, Kusano K, Kubozono O, et al. Association between arterial stiffness and estimated glomerular filtration rate in the Japanese general population. J Atheroscler Thromb. 2009;16(6):840-845.

13. Liu J, Liu H, Zhao H, Shang G, Zhou Y, Li L, Wang H. Descriptive study of relationship between cardio-ankle vascular index and biomarkers in vascular-related diseases. Clin Exp Hypertens. 2017;39(5):468-472.

14. Ponte B, Pruijm M, Ackermann D, Vuistiner P, Eisenberger U, Guessous I, Rousson V, et al. Reference values and factors associated with renal resistive index in a familybased population study. Hypertension. 2014;63(1):136142.

15. Imai E, Horio $M$, Nitta $K$, Yamagata $K$, Iseki $K$, Hara $\mathrm{S}$, Ura N, et al. Estimation of glomerular filtration rate by the MDRD study equation modified for Japanese patients with chronic kidney disease. Clin Exp Nephrol. 2007;11(1):41-50.

16. Cesarone MR, Belcaro G, Carratelli M, Cornelli U, De Sanctis MT, Incandela L, Barsotti A, et al. A simple test to monitor oxidative stress. Int Angiol. 1999;18(2):127-130.

17. Schisterman EF, Perkins NJ, Liu A, Bondell H. Optimal cut-point and its corresponding Youden Index to discriminate individuals using pooled blood samples. Epidemiology. 2005;16(1):73-81.

18. Raff U, Schmidt BM, Schwab J, Schwarz TK, Achenbach $\mathrm{S}$, Bar I, Schmieder RE. Renal resistive index in addition to low-grade albuminuria complements screening for target organ damage in therapy-resistant hypertension. J Hypertens. 2010;28(3):608-614.

19. Toledo C, Thomas G, Schold JD, Arrigain S, Gornik HL, Nally JV, Navaneethan SD. Renal resistive index and mortality in chronic kidney disease. Hypertension. 2015;66(2):382-388.

20. Calabia J, Torguet P, Garcia I, Martin N, Mate G, Marin A, Molina C, et al. The relationship between renal resistive index, arterial stiffness, and atherosclerotic burden: the link between macrocirculation and microcirculation. J Clin Hypertens (Greenwich). 2014;16(3):186-191.

21. Geraci G, Mule G, Geraci C, Mogavero M, D'Ignoto F, Morreale M, Foraci AC, et al. Association of renal resistive index with aortic pulse wave velocity in hypertensive patients. Eur J Prev Cardiol. 2015;22(4):415-422.

22. Safar ME, London GM, Plante GE. Arterial stiffness and kidney function. Hypertension. 2004;43(2):163-168.

23. Saji N, Toba K, Sakurai T. Cerebral Small Vessel Disease and Arterial Stiffness: Tsunami Effect in the Brain? Pulse (Basel). 2016;3(3-4):182-189.

24. Andrikou I, Tsioufis C, Konstantinidis D, Kasiakogias A, Dimitriadis K, Leontsinis I, Andrikou E, et al. Renal resistive index in hypertensive patients. J Clin Hypertens (Greenwich). 2018;20(12):1739-1744.

25. Sinha N, Dabla PK. Oxidative stress and antioxidants in hypertension-a current review. Curr Hypertens Rev. 2015;11(2):132-142.

26. Sedeek M, Nasrallah R, Touyz RM, Hebert RL. NADPH oxidases, reactive oxygen species, and the kidney: friend and foe. J Am Soc Nephrol. 2013;24(10):1512-1518.

27. Masugata H, Senda S, Murao K, Inukai M, Himoto T, 
Hosomi N, Okada H, et al. Association between urinary 8-hydroxydeoxyguanosine, an indicator of oxidative stress, and the cardio-ankle vascular index in hypertensive patients. J Atheroscler Thromb. 2012;19(8):747-755.

28. Chotimol P, Saehuan C, Kumphune S. Correlation between cardio-ankle vascular index and biomarkers of oxidative stress. Scand J Clin Lab Invest. 2016;76(2):105-111.

29. Hitsumoto T. Clinical Impact of blood testosterone concentration on cardio-ankle vascular index in female patients with type 2 diabetes mellitus. Cardiol Res. 2019;10(1):9-17.

30. Uramatsu T, Nishino T, Obata Y, Sato Y, Furusu A, Koji $\mathrm{T}$, Miyazaki $\mathrm{T}$, et al. Involvement of apoptosis inhibitor of macrophages in a rat hypertension model with nephrosclerosis: possible mechanisms of action of olmesartan and azelnidipine. Biol Pharm Bull. 2013;36(8):12711277.

31. Zha D, Yao T, Bao L, Gao P, Wu X. Telmisartan attenuates diabetic nephropathy progression by inhibiting the dimerization of angiotensin type-1 receptor and adiponectin receptor-1. Life Sci. 2019;221:109-120.

32. Abdel Kawy HS. Aliskiren and valsartan in combination is a promising therapy for hypertensive renal injury in rats. Clin Exp Hypertens. 2018;40(6):560-568.
33. Watanabe S, Okura $\mathrm{T}$, Kurata M, Irita J, Manabe $\mathrm{S}$, Miyoshi K, Fukuoka T, et al. Valsartan reduces serum cystatin $\mathrm{C}$ and the renal vascular resistance in patients with essential hypertension. Clin Exp Hypertens. 2006;28(5):451-461.

34. Kinouchi K, Ichihara A, Sakoda M, Kurauchi-Mito A, Murohashi-Bokuda K, Itoh H. Effects of telmisartan on arterial stiffness assessed by the cardio-ankle vascular index in hypertensive patients. Kidney Blood Press Res. 2010;33(4):304-312.

35. Miyashita Y, Saiki A, Endo K, Ban N, Yamaguchi T, Kawana H, Nagayama D, et al. Effects of olmesartan, an angiotensin II receptor blocker, and amlodipine, a calcium channel blocker, on Cardio-Ankle Vascular Index (CAVI) in type 2 diabetic patients with hypertension. J Atheroscler Thromb. 2009;16(5):621-626.

36. Izuhara M, Shioji K, Kadota S, Baba O, Takeuchi Y, Uegaito T, Mutsuo S, et al. Relationship of cardio-ankle vascular index (CAVI) to carotid and coronary arteriosclerosis. Circ J. 2008;72(11):1762-1767.

37. Tanaka A, Tomiyama H, Maruhashi T, Matsuzawa Y, Miyoshi T, Kabutoya T, Kario K, et al. Physiological diagnostic criteria for vascular failure. Hypertension. 2018;72(5):1060-1071. 